\title{
No es turismofobia, es lucha de clases. Políticas urbanas, malestar social y turismo en un barrio de Barcelona
}

\author{
It is not tourismphobia, it is class struggle. \\ Urban policies, social unrest and tourism in a neighborhood \\ of Barcelona
}

José A. Mansilla López*

Citar este artículo como: Mansilla López, J. A. (2019). No es turismofobia, es lucha de clases. Políticas urbanas, malestar social y turismo en un barrio de Barcelona. Revista Nodo, 13(26), pp. 42-60

\section{Resumen}

Las protestas contra los excesos del turismo llevan varios años copando las portadas de periódicos de todo el mundo. En Barcelona, un nuevo neologismo, turismofobia, parece acompañar -y calificar- a las distintas manifestaciones que adopta el malestar social en torno a algunas de sus efectos y prácticas principales. Mediante una aproximación etnográfica de más de dos años a la plataforma \#EnsPlantem, Veïns en Perill d'Extinció, el presente artículo pretende mostrar el papel desempeñado por este movimiento social frente a la aplicación de políticas urbanas y urbanísticas contemporáneas de corte neoliberal vinculadas al proceso de turistificación que vive la ciudad, así como el barrio del Poblenou.

Palabras clave: Barcelona, barrios, turistificación, gentrificación, malestar urbano

\section{Abstract}

The protests against the excesses of tourism have been starring the newspapers' covers around the world for several years. In Barcelona, a new neologism, turismofobia, seems to accompany -and qualify - the different manifestations that social unrest takes over some of its effects and main practices. Through a more than two-year ethnographic approach to the platform \#EnsPlantem, Veïns en Perill d'Extinció, this article aims to show the role played by this type of movements around the application of neoliberal contemporary urban policies linked to touristification process that is living the city and also the neighborhood of Poblenou.

Keywords: Barcelona, neighbors, touristification, gentrification, urban unrest.

Fecha de recepción: 7 de febrero de 2019 • Fecha de aceptación: 26 de marzo de 2019

* Departamento de Ciencias Sociales y Comunicación, Escuela Universitaria de Turismo Ostelea - Universitat de Lleida (UdL), Catalunya; Observatori d'Antropologia del Conflicte Urbà (OACU). Correo electrónico: joseamansilla@hotmail.com. Los resultados de la investigación aquí presentada han sido parcialmente publicados en los artículos "El curt estiu de la turismefòbia. Moviments socials i conflicte urbà al barri del Poblenou, Barcelona”, originalmente en catalán en el número 15, octubre 2018, de la Revista Andaluza de Antropología, y en "Vecinos en peligro de extinción. Turismo urbano, movimientos sociales y exclusión socioespacial en Barcelona”, en el número 16, vol. 2, de la Revista de Turismo y Patrimonio Cultural PASOS. 


\section{Introducción}

El 19 de junio de 2018, un pequeño grupo de militantes de la organización de izquierda juvenil independentista catalana Arran se encadenó al conocido dragón del Park Güell con el objetivo de "denunciar la massificació turística i els seus efectes nocius [...]"1. El simbólico acto, con una enorme repercusión en las redes sociales (Vera, 2018), había sido precedido de un comunicado en el cual la formación política calificaba al modelo turístico puesto en marcha en Barcelona y otros emplazamientos como insostenible, tanto a nivel humano como territorial ${ }^{2}$. Sin embargo, ésta no fue la única manifestación de descontento protagonizada por Arran durante el verano del citado año. Pocos días después, el 9 de julio, dos de sus activistas irrumpieron en uno de los conocidos Bus Turístic ${ }^{3}$ desplegando una pancarta en su lateral donde era posible leer "Aturem la massificació turística als Països Catalans"4, además de lanzar un par de botes de humo de colores a la parte posterior descubierta del vehículo. El hecho, que no generó ni desperfectos ni supuso en ningún momento una alteración del servicio, se tildó, desde el Ayuntamiento de la ciudad, como "una de tantas iniciativas simbólicas que se producen en la ciudad", aunque sí fue ampliamente recogido por la prensa local y condenado frontalmente por

1 "Denunciar la masificación turística y sus efectos nocivos [...]”. A lo largo del texto, las citas explícitas en catalán aparecerán traducidas a pie de página. El acto de denuncia fue difundido a través de las redes sociales de Arran Poblenou (@ArranP9). Para más información ver: https://twitter.com/ ArranP9/status/1008972314766127104

2 Para más información ver: https://arran.cat/blog/ 2018/06/17/el-model-turistic-actual-als-paisos-catalans-esinsostenible-insostenible-a-nivell-huma-i-insostenible-pelterritori/

3 Autobuses que circulan por la ciudad en itinerarios determinados de interés turístico.

4 "Detengamos la masificación turística en los Países Catalanes". Los Païses Catalans comprenderían las áreas de habla catalana que actualmente se encuentran en territorios del Estado español y Francia. la oposición política municipal ${ }^{5}$. Solo un mes más tarde, el día 9 de agosto, Arran volvió a realizar otros de sus actos reivindicativos expropiando cinco de las bicicletas de una conocida empresa de alquiler para, con posterioridad, sortearlas entre aquellos seguidores y seguidoras de su perfil en una conocida red social que contribuyeran a hacer visible la acción ${ }^{6}$.

Arran no es el único colectivo -aunque sí el que cuenta con una mayor organización y estructura territorial, lo que hace que sus manifestaciones sean de las más conocidas por la opinión públicaque lleva a cabo este tipo de acciones o intenta trasladar un mensaje de malestar por los efectos del turismo en la ciudad. Las paredes de barrios como Vallcarca, Poblenou o el Gòtic (ver Figura 1), los cuales cuentan con algunos de los principales elementos de atracción para los turistas, vienen denunciando desde hace años -pública o anónimamente- la situación que viven sus vecinos y vecinas, así como las consecuencias que el turismo masivo les está ocasionando.

Aunque la prensa viene recogiendo artículos y columnas de opinión sobre el papel conflictivo del turismo en la ciudad condal desde hace bastante tiempo $^{7}$, y movimientos sociales como Gràcia, cap a on vas?8 o la Assembea de Barris per un Turisme Sostenible (ABTS) han llevado a cabo, no solo importantes acciones de denuncia sobre, por

5 A modo de ejemplo ver: La Vanguardia, 09/08/2018 https://www.lavanguardia.com/local/barcelona/ 20180709/45785832572/arran-irrumpe-en-un-bus-turis tico-de-barcelona-y-cuelga-una-pancarta-contra-el-turismomasivo.html o El Periódico, 09/07/2018 https://www.el periodico.com/es/politica/20180709/arran-ocupa-busturistico-barcelona-6932365

6 Para más información: https://twitter.com/Arran_jo vent/status/1027453975447130112

7 Huete y Manteco (2018) recogen en su artículo de la Revista PASOS cuarenta referencias a la turismofòbia solo en el ámbito estatal, aunque también señalan referencias a la misma en diarios europeos como The Independent y el Daily Mail.

8 Para más información ver: https://graciacapaonvas.word press.com/ 


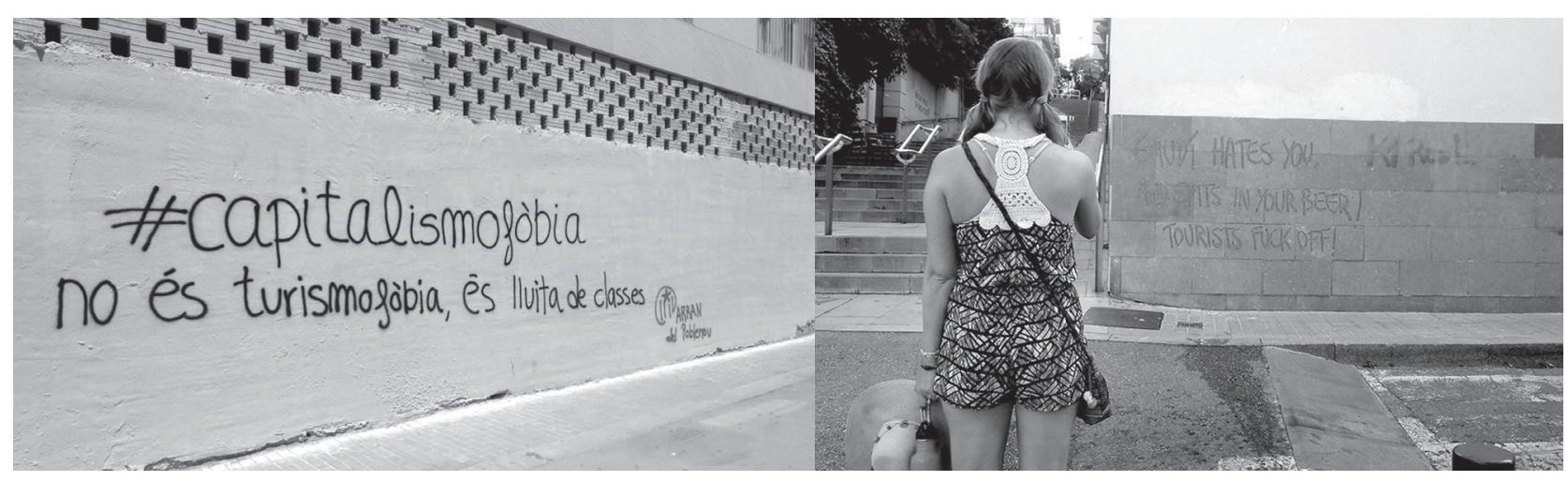

Figura 1. Grafitis en los barrios del Poblenou y Vallcarca (19/06/2018 y 30/07/2018) Fuente: @LateHumans

ejemplo, el papel de plataformas como Airbnb en el tejido social de la ciudad, sino también encuentros internacionales y debates propositivos sobre esta cuestión ${ }^{9}$, es posible afirmar que la interrelación entre turismo y ciudad tomó un impulso notorio definitivo durante la campaña turística de 2017 (Mansilla, 2018a).

En el barrio del Poblenou, este tipo de acciones directas han tenido también cierta relevancia. Durante junio y julio de 2018, colectivos vecinales y juveniles organizaron una serie de concentraciones y charlas que intentaron poner el acento en la relación entre turismo y gentrificación ${ }^{10}$. No obstante, un año antes y en clave más directa, parte de los participantes en una manifestación convocada el 5 de mayo por la plataforma vecinal \#EnsPlantem, la cual había aglutinado más de trescientas personas en protesta contra "el alto precio de los alquileres por la presión turística en el barrio y la gentrificación" (Savall, 2017), había llegado a lanzar huevos y globos con pintura contra las fachadas de dos hoteles de la zona. La acción contó, además, con ciertos momentos de tensión, ya que además de la pintura y los huevos, alguno de los manifestantes arrojó un bote de humo a las puertas de uno de los establecimientos.

9 Para más información ver: https://assembleabarris. wordpress.com/forumveinalturisme/ y https://assembleaba rris.wordpress.com/2018/05/08/programa-del-2n-forumveinal-sobre-turisme-18-i-19-de-maig/

10 Para más información ver: https://twitter.com/xeme neiap9/status/1003934646608986113
El incidente provocó, como no podía ser de otra manera, la inmediata respuesta por parte del Ayuntamiento de la ciudad, el cual condenó "els incidents a Poblenou. El que cal és aplicar amb fermesa el PEUAT, combatre els lloguer abusius i l'especulació als barris"11.

Los hechos hasta aquí relatados evidencian la conflictividad que el turismo, bajo ciertas circunstancias, puede llegar a provocar. Así, considerado tradicionalmente como una industria sin chimeneas, el turismo podría haber subestimado "los impactos ambientales, sociales, culturales, económicos, religiosos, etc., [que genera como] actividad [...], entendiéndose como impactos los choques o consecuencias de la actividad turística en la diferentes áreas mencionadas" (Gruter, 2013). En lo referente al discurso turismofóbico, los sociólogos Raquel Huete y Alejandro Mantecón (2018) distinguen dos líneas principales a la hora de presentar el fenómeno: por un lado, una línea deslegitimadora basada en "una política orientada al logro de beneficios económicos inmediatos a partir del aumento de la llegada de turistas, en detrimento de la planificación de un desarrollo sostenible y de la gestión y adaptación de la demanda a las características específicas de cada destino" (p. 16), y, por otro lado, una línea "critica [con] los efectos del

11 "los incidentes en el Poblenou. Lo que hace falta es aplicar con firmeza el PEUAT, combatir los alquileres abusivos y la especulación en los barrios". Para más información ver: https://twitter.com/G_Pisarello/status/860875813918576641 
turismo masivo en las ciudades [que] se incorpora a un ideario contestatario más amplio en el que se articulan expresiones antiglobalizacion capitalista íntimamente asociadas con movimientos sociopolíticos que plantean diferentes reivindicaciones" (p. 16) ${ }^{12}$. Así, como señala el antropólogo Claudio Milano "en los últimos años, los movimientos sociales y el turismo han empezado a tener una relación muy cercana" (2017, p. 6), de forma que podrían ser considerados como factores negativos al interponerse en la necesaria estabilidad social y política que requiere la continuación del proceso de acumulación capitalista (Cordero, 2006).

En definitiva, mientras una orientación se mostraría pragmática y posibilista, encajando perfectamente en el marco de las políticas de corte neoliberal implementadas en las ciudades europeas durante las últimas décadas (Harvey, 2001 y 2013), la segunda estaría vinculada a la consideración de la ciudad como mercancía (Lefebvre, 1969; Delgado, 2017; Mansilla, 2018b), mostrando unas relaciones sociales conflictuales insertas, y aparentemente ocultas, tras las dinámicas turístico-urbanizadoras, las cuales cuentan, además, con el protagonismo de unos movimientos sociales que intentan denunciar la situación y proponer alternativas como agentes colectivos.

\section{Metodología e hipótesis}

En lo relativo al presente trabajo me centraré en la última de las aproximaciones. A través del análisis a un fenómeno emergente, la plataforma \#EnsPlantem en el Poblenou, Barcelona, diseccionaré el papel que juegan los movimientos sociales en el marco de las políticas neoliberales urbanas. Para ello me centraré, principalmente, en las diferentes respuestas que \#EnsPlantem ha dado a la dinámica que, según su propio diagnóstico, vive el barrio: la turistificación, entendiendo por tal aquel

12 El psicólogo social Horacio Espinosa señala la existencia de intentos de despolitizar, y deslegitimar, el malestar subjetivo que genera el turismo en determinados emplazamientos (Zepeda, 2017). proceso por el cual se transforma un bien histórico, cultural o natural - pero también un barrio como entramado social y espacial-, en un producto valioso para el mercado turístico (Zúñiga, 2014).

La metodología usada en este artículo es principalmente cualitativa (Berg, 2007), como no podía ser de otra forma tratándose de una aproximación etnográfica. Sin embargo, ésta se verá complementada con otra de tipo cuantitativo (Bernard, 2006) con el objetivo de realizar una aproximación metodológica bidimensional (Giner, 1976) o, incluso, una triangulación digital teniendo en cuenta la consideraciones de autores como Posthill (2015), en un intento de apuntalar al máximo la proposición inicialmente presentada. De este modo, el primer paso a la hora de llevar a cabo el proceso etnográfico (Velasco y Díaz de Rada, 1997) fue la realización de una revisión en profundidad de bibliografía relevante relacionada con el tipo de dinámica estudiada, no solo libros o artículos vinculados, sino también noticias, declaraciones, páginas webs y la participación en redes sociales de los principales actores involucrados. Ésta aparecerá referenciada conforme vaya siendo útil a la argumentación planteada.

El trabajo de campo para la presente investigación se llevó a cabo entre los meses de mayo de 2016 y julio de 2018 y las técnicas utilizadas fueron, principalmente, la observación participante -en asambleas, acciones reivindicativas, ocupaciones, manifestaciones, foros y grupos de WhatsApp, Redes Sociales, etc.-, la realización de entrevistas y el mantenimiento de conversaciones y diálogos informales con los principales actores participantes.

La metodología etnográfica, además, fue considerada como adecuada para este tipo de investigación ya que permite una aproximación al objeto de estudio desde dentro, y admite describir e interpretar los procesos sociales poniendo especial atención en sus participantes. Para la realización del trabajo de campo no se establecieron diferencias basadas en el género ni en la edad. Con el objetivo de evitar repeticiones, se han seleccionado los extractos más representativos de las entrevistas y los acontecimientos observados. 


\section{Empresarialismo urbano, turismo y movimientos sociales}

No es hasta principios de la década del 2000 que los estudios urbanos comienzan a desmontar la consideración de que los usos turísticos y residenciales permanecían separados en las ciudades (Judd, 2003). Así, como señalan Russo y Richards (2016), los turistas buscan ahora un contacto más cercano con los locales; algo que, además, se ha convertido en una nueva experiencia a ofrecer por parte de los destinos.

Por otro lado, desde los años 70, las ciudades se han convertido en piezas fundamentales para los procesos de acumulación y circulación del capital (Harvey, 2007; Brenner, Pecky Theodore, 2015). Así lo muestran los ejemplos de ciudades americanas tan dispares como Valparaíso (Caimanque, 2015) y Río de Janeiro (Guterman et al, 2015) o, ya dentro del Estado español, Sevilla (Díaz, 2009 y 2016), Tenerife (García Herrera, Smith, y Mejías, 2007), Granada (Medela y Salguero, 2016) o la propia Barcelona (Delgado 2005 y 2007). Sin embargo, como bien recordaran Judd and Parkinson (1990), las políticas destinadas a tal fin suelen generar ciudades segmentadas que favorecen la afluencia de clases medias en detrimento de las bajas. A veces, esta determinación se encuentra, incluso, en su $A D N$ urbanístico. Este sería el caso, de nuevo, de la capital de Catalunya donde, tal y como recoge la geógrafa Rosa Tello, su Plan General Metropolitano de 1976 apostaba por "el mantenimiento en la comarca de personas de renta media y elevada" (1993, p. 513).

Por otro lado, esta búsqueda por mantener y atraer clases medias y capitales reforzaría el proceso de fragmentación y exclusión. Las propuestas elaboradas por autores como Richard Florida (2009a y 2009b) en base a las denominadas clases y ciudades creativas abundan en esa dirección. El objetivo de estas políticas descansaría sobre la idea de que la creación de atmósferas urbanas dedicadas a la producción cultural y el consumo acabarían funcionando como auténticos motores de redesarrollo (Lloyd, 2002). Ahora bien, esta aparición de grupos sociales con mayores ingresos y nuevas demandas desencadenaría la aparición de procesos, como el de gentrificación, muchos más amplios y menos miopes que las iniciales consideraciones sobre el tema de hace unas décadas -las cuales restringían dinámicas similares al mercado inmobiliario- y habrían acabado desembocando en toda una reconfiguración del paisaje de las ciudades en clave de clase (Smith, [1996] 2012; Slater, 2011).

Estos nuevos vecinos y vecinas de clase media reclamarían experiencias urbanas similares a los turistas, de forma que los efectos de ambas presencias, así como los procesos que generan, llegan a ser indistinguibles en el marco de los cambios urbanos (Fuller y Michel, 2014). Algunos autores (Hiernaux y González, 2014) llegan a denominar a estas dinámicas "gentrificación criolla" para el caso de las ciudades latinoamericanas. La diferencia con el modelo más clásico estribaría en que, por un lado, el turista aparece como un "productor del espacio"13 (Lefebvre, 2013), tanto simbólico como material y, por otro, no se produce una sustitución permanente de una clase social por otra, sino que las clases medias-bajas son desplazadas por habitantes no residentes, esto es, por turistas. Sin embargo, esta violencia simbólica (Bourdieu, 1997) que genera el turismo no es, hoy día, patrimonio exclusivo de las ciudades del hemisferio oriental, sino que los cambios en el paisaje urbano, las modificaciones en el comercio tradicional, etc., aparecen como un común denominador para urbes de todo el globo (Romero, 2001).

Esta manifestación de relaciones de poder asimétricas, disputas por el espacio y control social en la ciudad (Harvey, 2013) se presenta en estas situa-

13 El espacio que producirían -y encontrarían, en un proceso dialéctico-, los turistas coincidiría con aquel demandado por las clases medias, esto es, "un espejo de su realidad, representaciones sedantes, la imagen de un mundo social en el que tienen su lugar, preciso, etiquetado y asegurado" (Lefebvre, 2013: 345). 
ciones mediante una competencia por los recursos y los servicios que ofrece (Fuller y Michel, op. cit.), pero también a través de un impacto directo sobre los precios de la vivienda, la introducción de nuevas formas de consumo y, en general, las transformaciones en el entorno urbano.

En los últimos tiempos, diferentes autores provenientes, sobre todo, de Europa y Estados Unidos proponen abordar las investigaciones en torno a las tensiones generadas por las políticas urbanas neoliberales -en toda su amplitud-, y sus resistencias enfocando tres elementos fundamentales: la amplia gama y la heterogeneidad de los actores involucrados; la variedad de respuestas que los movimientos sociales pueden ofrecer $y$, por último, las propuestas para reconstruir la ciudad desde abajo (Mayer, 2016). De esta forma, manifiestan su insatisfacción "with the rationalist and empiricist social movement research paradigm" (Thörn, Mayer y Thrön, 2016, p. 22) de los análisis basados, por ejemplo, en la Estructura de Oportunidades Políticas (EOP), reclamando una vuelta a los trabajos de Castells ${ }^{14}$ en un intento de destronar su largo reinado.

En esta misma línea podríamos incluir a David Harvey cuando subraya que las prácticas de desposesión relacionadas con, por ejemplo, el mercado de la vivienda o la privatización del espacio urbano, se podrían considerar formas secundarias de explotación ya que, actualmente, constituirían parte de la piedra de bóveda de la acumulación del capital (2013). Así, el neoliberalismo, como proceso de reorganización de la producción capi-

14 Manuel Castells, en La Cuestión Urbana (1976), otorgaba a los movimientos sociales urbanos una potencial función transformadora y los equiparaba a los sindicatos clásicos de la esfera productiva. En obras posteriores, La ciudad y las masas: sociología de los movimientos sociales urbanos (1986), atemperó esta aproximación al fenómeno. Mucho más genéricas son las consideraciones establecidas por autores como Mario Diani (1992, 2010), Donatella della Porta (2009) y de forma conjunta Diani y Della Porta ([1999] 2006). Éstos ponen el foco, a la hora de definir los movimientos sociales, en su especificidad en la coordinación de acciones colectivas y en la constitución de redes de actores de un perfil amplio y heterogéneo. talista, crea nuevos actores históricos, diferentes constelaciones de intereses, las amenazas a estos intereses y las principales condiciones para las trasferencias del poder (Tilly, 1977) y su disputa.

Es mediante esta perspectiva que podrían analizarse movimientos y acciones como la Plataforma \#EnsPlantem, Veïns en Perill d'Extinció, de Barcelona, a la que dedicaré los siguientes párrafos.

\section{El largo invierno del descontento en el Poblenou}

Parafraseando a William Shakespeare, el barrio del Poblenou lleva padeciendo un invierno del descontento desde hace más de cincuenta años. Sin embargo, este descontento está menos vinculado a los versos del poeta inglés en torno a los hechos de Ricardo III, y más a las políticas neoliberales vividas por el conjunto de los británicos en la antesala de la llegada de Margaret Thatcher al poder en $1979^{15}$.

Desde los intentos de transformación de parte de su frente marítimo en una Copacabana barcelonesa (Arroyo, 1999) a través del conocido como Plan de la Ribera de 1965 (Tatjer, 1973; Navas, 2016), hasta las transformaciones operadas en el barrio como consecuencia de la construcción de la Vila Olímpica de los Juegos del 1992 (Makhlouf, 2014; Aricó, Mansilla y Stanchieri, 2016) y la tentativa de convertir este antiguo Manchester catalán en un SoHo Barcelonés mediante el Plan 22@ (Marrero, 2003), los antiguos terrenos ocupados por una de las más altas concentraciones de tejido fabril del continente han sido testigos del cambio de orientación de una ciudad tradicionalmente industrial a otra volcada en el consumo y los servicios (Capel, 2005 y 2016), con especial incidencia en aquellas actividades vinculadas con las nuevas

15 Se atribuye al último Primer Ministro laborista de los 70s, la frase "now, is the Winter of our discontent". The Guardian. Para más información ver: https://www. theguardian.com/news/2011/jan/10/weatherwatch-jimcallaghan-winter-discontent 
tecnologías de la información y la comunicación (TIC) (Mansilla, 2014).

El paradigma de la nueva economía, sin embargo, no ha tenido finalmente presencia considerable ni en el Poblenou, ni en la ciudad de Barcelona ${ }^{16}$. Como demuestran los datos disponibles, para el año 2015, solo el 30\% de las empresas instaladas en el 22@ se encontraban bajo el paraguas de las nuevas tecnologías, siendo el 52,7\% empresas ya existentes que se trasladaban al nuevo Distrito, mientras que casi el $70 \%$ lo copaban hoteles y compañías vinculadas a los seguros, los servicios financieros y el marketing (Ajuntament de Barcelona, 2016a.). Así, el proceso de desindustrialización -de tipo clásico- que tomó nuevos bríos con planes como el 22@ se vio acompañado, no solo por una dinámica de especulación urbanística y financiera, sino también por un incremento significativo de hoteles (Figura 2) y otros alojamientos turísticos que han buscado compensar el fracaso relativo de la llegada de empresas de la nueva economía (Clarós, 2013; Charnock, Purcell y Ribera-Fumaz, 2014).

Esta deriva hacia los servicios y el turismo que ha vivido el 22@, supuestamente ajena a las intenciones iniciales de la administración municipal impulsora del mismo, está en línea con la conversión de Barcelona en una ciudad turística comparable a otros destinos ampliamente consolidados -como París, Roma o Londres-, situándola como la tercera ciudad de Europa y décima, a nivel mundial, en cuanto a número de visitantes y gasto, y como la quinta ciudad europea y la vigésima del mundo más visitada (Ajuntament de Barcelona, 2015), además de cómo el tercer destino europeo en la celebración de congresos y otros eventos (Castán, 2018). Esto ha hecho, tal y como indica el Plan Estratégico de Turismo de Barcelona 2020, que el turismo sea "parte inherente y constitutiva

16 A mediados de 2018, salta la noticia de que Facebook se instalaría en la antigua Torre Abgar, actual Torre Glòries, en el 22@. Sin embargo, finalmente lo que se instala es una subcontrata de la compañía, el Competence Call Center (CCC), encargada de controlar las fake news para Europa. Para más información ver: https://elpais.com/economia/2018/05/07/ actualidad/1525714881_102628.html

\begin{tabular}{|c|c|c|}
\hline $\begin{array}{l}\text { Hotel Hilton Diagonal } \\
\text { Mar Barcelona }\end{array}$ & $\begin{array}{l}\text { Passeig del Taulat, } \\
\text { 262-264 (Barcelona) }\end{array}$ & Hotel $5^{*}$ \\
\hline Hotel Amrey Diagonal & $\begin{array}{l}\text { Avinguda Diagonal, } \\
161 \text { (Barcelona) }\end{array}$ & Hotel 3* \\
\hline Hotel BGG 4 Barcelona & $\begin{array}{l}\text { Carrer del Doctor Trueta, } \\
164 \text { (Barcelona) }\end{array}$ & Hotel 4* \\
\hline Hotel Barcelona Princess & $\begin{array}{l}\text { Avinguda Diagonal, } \\
1 \text { (Barcelona) }\end{array}$ & Hotel 4* \\
\hline $\begin{array}{l}\text { Hotel Confortel Barce- } \\
\text { lona }\end{array}$ & $\begin{array}{l}\text { Carrer de Ramon Turró, } \\
\text { 196-198 (Barcelona) }\end{array}$ & Hotel $4 *$ \\
\hline Hotel Barceló Atenea Mar & $\begin{array}{l}\text { Passeig de Garcia Fária, } \\
\text { 37-497 (Barcelona) }\end{array}$ & Hotel 4* \\
\hline Hotel Sallés Pere IV & $\begin{array}{l}\text { Carrer de Pallars, } \\
\text { 128-130 (Barcelona) }\end{array}$ & Hotel $4^{*}$ \\
\hline Hotel Apsis Porta Marina & $\begin{array}{l}\text { Carrer de Sancho de Ávila, } \\
\text { 32-34 (Barcelona) }\end{array}$ & Hotel $4 *$ \\
\hline Hotel Me Barcelona & $\begin{array}{l}\text { Avinguda Diagonal, } \\
\text { 272-286 (Barcelona) }\end{array}$ & Hotel 5* \\
\hline $\begin{array}{l}\text { Hotel \& Spa Villa } \\
\text { Olimpic@Suites }\end{array}$ & $\begin{array}{l}\text { Carrer de Pallars, } \\
121 \text { (Barcelona) }\end{array}$ & Hotel 4: \\
\hline $\begin{array}{l}\text { Hotel Rafaelhoteles } \\
\text { Diagonal Port }\end{array}$ & $\begin{array}{l}\text { Carrer de Lope de Vega, } \\
4 \text { (Barcelona) }\end{array}$ & Hotel 4* \\
\hline Hotel AC Barcelona & $\begin{array}{l}\text { Passeig del Taulat, } \\
278 \text { (Barcelona) }\end{array}$ & Hotel 4* \\
\hline $\begin{array}{l}\text { Hotel Husa Barcelona } \\
\text { Mar }\end{array}$ & $\begin{array}{l}\text { Carrer de Provencals, } \\
10 \text { (Barcelona) }\end{array}$ & Hotel 4* \\
\hline $\begin{array}{l}\text { Holiday Inn Express } \\
\text { Barcelona City 22@ }\end{array}$ & Pallars, 203 (Barcelona) & Hotel 3* \\
\hline $\begin{array}{l}\text { Hotel Ibis Barcelona Pza } \\
\text { Glories } 22\end{array}$ & $\begin{array}{l}\text { Calle Ciutat de Granada } \\
\text { 99, (Barcelona) }\end{array}$ & Hotel 2* \\
\hline
\end{tabular}

Figura 2. Hoteles, categoría y localización exacta en el Distrito 22@. Fuente: Ajuntament de Barcelona, 2016

del fenómeno urbano actual" (Ajuntament de Barcelona, 2016b), de forma que, como actividad socioeconómica, da forma a la ciudad al mismo tiempo, y de forma dialéctica, que la ciudad determina las posibilidades del turismo. Además, ha llevado a la propia institución municipal a plantear el proceso Repensem el 22@, el cual persigue "endegar un procés de participació ciutadana per repensar conjuntament una estratègia davant dels actuals reptes socials, econòmics i urbanístics del Poblenou i el 22@"17.

17 "Poner en marcha un proceso de participación ciudadana para repensar conjuntamente una estrategia ante los actuales retos sociales, económicas y urbanísticos del Poblenou y el 22@". Para más información ver: https://www.decidim. barcelona/processes/Repensem22a 


\section{\#EnsPlantem, Veins en Perill d'Extinció}

El 20 de mayo de 2016, una pequeña multitud se dio cita en uno de los emplazamientos más emblemáticos del Poblenou; una pequeña rotonda conformada por el cruce de la calle Doctor Trueta y la Rambla del barrio, justo frente al Casino de l'Aliança, señero teatro de Barcelona que actualmente comparte edificio con un concurrido restaurante. El arbolado y antiguo Passeig del Triomf, verdadero eje de la vida social del Poblenou y su principal punto de encuentro, es, actualmente, la única Rambla de toda Barcelona que desemboca en la playa, hecho que le ha otorgado un atractivo considerable. La convocatoria había sido realizada por tres mujeres que contaban con una nutrida experiencia dentro de los movimientos sociales del barrio y se vino difundiendo, desde unos días antes, a través de diferentes vías (listas de correo electrónico, cartelería variada, mensajes de Whatsapp, boca a boca, etc.), tanto entre diferentes colectivos y personas del tejido social local como ante el vecindario general.

Sentada en el suelo, la improvisada asamblea atrajo la atención de los paseantes, muchos de los cuales se detenían sorprendidos por una acción como aquella en tan significativo lugar. Sin más, las tres mujeres expusieron el motivo principal del encuentro: conformar una plataforma vecinal para luchar contra el proceso de turistificación que, según ellas, vivía el barrio, así como contra sus efectos, entre los que citaron el incremento de los precios de la vivienda y los alquileres, el cambio en la fisionomía del entorno -la aparición de establecimientos turísticos y comercios que poco o nada tenían que ver con las necesidades más cotidianas de los vecinos y vecinas- y la superpoblación de bares y terrazas en los tradicionales espacios de socialización del barrio, destacando entre los mismos, la propia Rambla, algo que estaba generando la expulsión de todos aquellos que no podían adaptarse a la dinámica de transformación que estaba viviendo el Poblenou. Nacía así \#EnsPlantem, Veïns en Perill d'Extinció.
Entre las primeras decisiones que tomó la plataforma \#EnsPlantem estuvo la realización de una serie de acciones en el espacio urbano del barrio con el objetivo de hacer visible las reivindicaciones planteadas. En este sentido se convocó, para el 5 de junio de 2016, lo que se denominó una "Ruta de l'Especulació" (Ver Figura 3). Ésta consistió en un pasacalle que recorrió diversos emplazamientos del Poblenou considerados como especialmente relevantes para los miembros de la asamblea. Entre los mismos se encontraron espacios que, en breve, acogerían establecimientos hoteleros, así como antiguos solares convertidos en huertos urbanos, como el denominado Hort Indignat $1^{18}$, espacio ocupado por la extinta Assemblea Social del Poblenou (ASP9), heredera del movimiento 15M en el barrio, y que pertenecía al denominado SAREB (Sociedad de Gestión de Activos procedentes de la Reestructuración Bancaria) o Banco Malo, esto es, el organismo constituido por el Gobierno del Estado para adquirir activos inmobiliarios pertenecientes a entidades financieras en proceso de saneamiento.

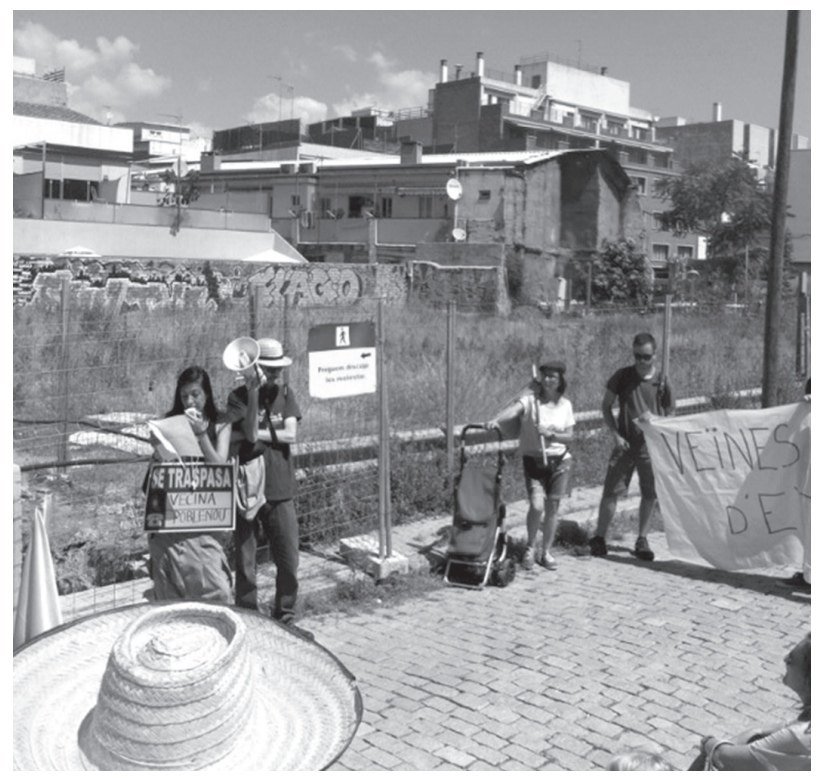

Figura 3. La Ruta de l'Especulació a su paso por uno de los antiguos huertos (05-06-2016). Fuente: @EnsPlantemP9

18 En agosto de 2018, fecha en la que este artículo es escrito, el Hort hace tiempo que ha sido desalojado por sus nuevos propietarios, los cuales persiguen la construcción en el solar de un complejo de viviendas de gama alta. 
El destino final del itinerario era la "recuperació d'un espai verd pel barri" y la realización de "una plantada popular de flors", hechos que se produjeron cuando los participantes en la Ruta ocuparon, de forma simbólica ${ }^{19}$, un solar de unos $10.000 \mathrm{~m}^{2}$ situado en el cruce de las calles Llacuna, Llull, Roc Boronat y Ramón Turró y donde, además de estar pendiente la ubicación de una zona verde por parte del Ayuntamiento de la ciudad, estaba prevista la construcción de dos nuevos hoteles. Según los ocupantes, estos dos hoteles supondrían un añadido de 1.000 plazas hoteleras para un barrio donde "los inmuebles se han encarecido, [se] abren comercios que no satisfacen necesidades de los vecinos sino de los turistas y [se da una] presencia cada vez más masiva de visitantes extranjeros en los bares y terrazas" (La Vanguardia, 2016).

De esta forma, la idea tras este movimiento social se vehicularía inicialmente alrededor de a) una lucha contra el incremento del precio de la vivienda, b) las transformaciones del paisaje urbano y c) determinadas concepciones en torno a la forma de consumir el espacio alejadas de las más tradicionales por parte de los vecinos y vecinas. Como me señaló Rosa, una de las fundadoras de la Plataforma, ésta comienza su andadura porque "no se estaba haciendo nada, faltaba un movimiento en el barrio que luchara por el derecho a la vivienda [...] y el espacio público. Había que plantarse $\mathrm{e}^{20}$ literal y metafóricamente".

Las primeras reuniones preparatorias de \#EnsPlantem se llevaron a cabo, precisamente, en algunos de los espacios que habían sido denunciados y señalados en la "Ruta de l'Especulació" y por participantes en movimientos sociales ya consolidados en el Poblenou. Volviendo a Rosa,

19 "Recuperación de un espacio verde para el barrio" y "una plantación popular de flores”. En agosto de 2018, más de dos años después de la ocupación, el Hort de la Vanguardia sigue funcionando.

20 \#EnsPlantem traducido al castellano significaría Nos Plantamos. la idea se fraguó en el Huerto 1 [...], llamamos a gente de la Flor ${ }^{21}$, del Octubre ${ }^{22}$, gente cercana que pensamos que estarían interesados en participar y nos reunimos durante dos meses [...] Siempre habíamos dicho que había que comenzar a trabajarlo en el Poblenou, montar algo...

En relación a esto, Roser, otra de las entrevistadas, subraya las posibilidades que ofrece el espacio urbano para el nacimiento de nuevos movimientos, así como para el desarrollo de acciones, cuando señala que

el barrio ha vivido ciclos de movilizaciones [...], llevaba un tiempo más parado, bueno, haciendo cosas pero a nivel más interno, y ahora este pico ha sido por el tema del turismo, pero evidentemente esto no habría sido posible sin movilizaciones anteriores y por personas que han participado en esas movilizaciones.

Algo que estaría en la línea de lo que Walter Nicholls (2008, p. 848) señalara en relación a las redes de insurgencia urbana, esto es, aquellas relaciones especiales y espaciales que se establecen entre diferentes actores en ese medio único que es la ciudad.

\section{El incremento del precio de la vivienda}

El eje fundamental sobre el que giran las reivindicaciones de \#EnsPlantem es el incremento del precio de la vivienda, tanto de alquiler como de compra, elemento este que acentuaría el carácter material de la lucha de la plataforma como movimiento social en la ciudad (Thörn, 2012).

Las estadísticas del Institut Català del Sòl (INCASOL) con respecto al precio de la vivienda en

21 Ateneu la Flor de Maig. Antigua cooperativa que, tras un periodo de ocupación, en 2014 fue comprada por el Ayuntamiento de Barcelona y cedida a la Associació Flor de Maig para usos culturales y sociales. Para más información ver: https://laflordemaig.cat/

22 Casal Independentista del Poblenou. Para más información ver: https://www.facebook.com/octubrepoblenou/ 
el Poblenou indican que, desde el año 2013, primer dato disponible, hasta 2017, el $\mathrm{m}^{2}$ de las casas en compra/venta ${ }^{23}$ pasó de los $3.117,3 €$ a los 4.347,4 €, esto es, casi un 40\% de incremento para el periodo de cinco años. Para la vivienda en alquiler ${ }^{24}$, el incremento es del $32,13 \%$, desde los $10,57 € / \mathrm{m}^{2}$ del 2014, hasta los $13,97 € / \mathrm{m}^{2}$ de 2017 . Si imaginamos una superficie media de las viviendas de entorno a los $70 \mathrm{~m}^{2}$-el 62,6\% de las viviendas del barrio tienen una superficie que oscila entre los 60 y los $120 \mathrm{~m}^{2}$ ${ }^{25}$-, esto hubiera supuesto pasar de los 739,90 euros/ mes a los 977,61 euros/mes de renta de alquiler.

Los precios alcanzados hacen imposible la vida en el barrio a los vecinos y vecinas de la zona. Así relataba Roser su situación personal al respecto:

"Me he tenido que ir del barrio, al Clot, que tampoco está tan lejos, que estoy bien, pero buscaba por aquí pero no lo encontré [...], lo único que encontrabas eran zulos de 40 metros cuadrados y claro, si querías compartir piso con alguien, no puedes... y aparte, muy caros... así que te ibas para el Besòs o para arriba, aunque el Clot $^{26}$ también está subiendo bastante".

Para enfrentar esta situación, en febrero de 2018, conjuntamente con la Associació de Veïns i Veïnes del Poblenou (AVVP9) y otras entidades del barrio, \#EnsPlantem puso en marcha la Comissió d'Habitatge del Poblenou (la Comissió actualmente sigue funcionando. Ver Figura 4). El objetivo de la Comissió es, en palabras de Robert, uno de sus miembros,

23 El dato del precio del $\mathrm{m}^{2}$ presentado considera tanto la vivienda nueva como la de segunda mano. La fuente que usa el INCASOL es la del Colegio de Registradores de la Propiedad, Bienes Muebles y Mercantiles de España.

24. La estadística del mercado del alquiler en Catalunya está basada en el registro de las fianzas de alquiler depositadas en el INCASOL.

25 Datos del Gabinet Tènic de Programació del Ayuntamiento de Barcelona. Para más información: http:// www.bcn.cat/estadistica/castella/documents/barris/68_MA_ Poblenou_2016.pdf

26 Tanto el barrio del Clot como el Besòs forman parte del Distrito Sant Martí, una de las divisiones administrativas en las que está dividida Barcelona.
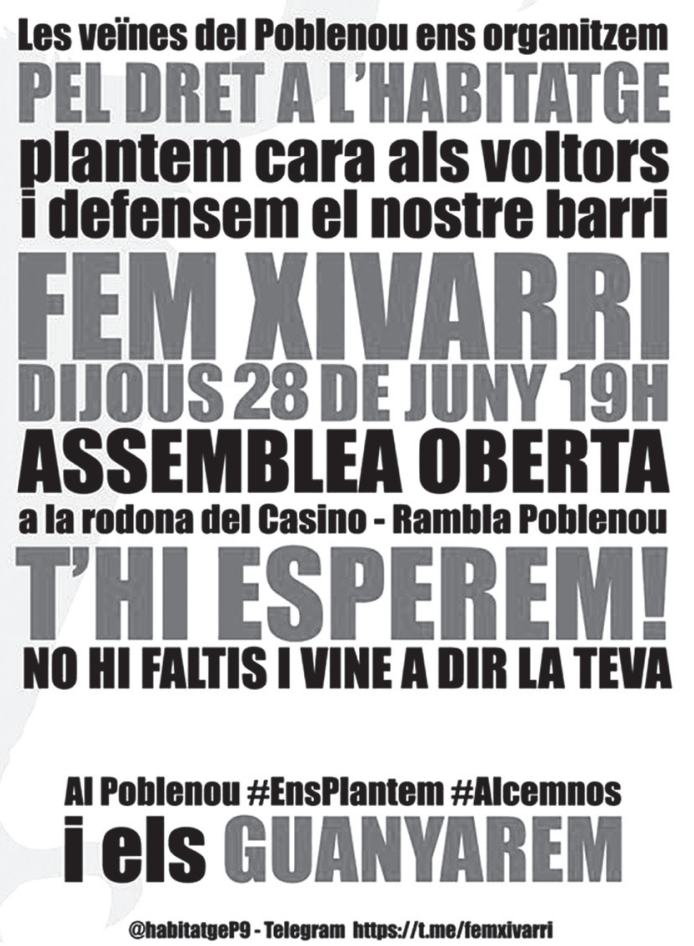

Figura 4. Convocatoria de Asamblea Abierta de la Comissió d'Habitatge del Poblenou (28-06-2018)

informarse de casos de expulsión de vecinos y vecinas por los precios del alquiler y, después, conseguir que el vecindario se organice para poder negociar los casos de manera colectiva, que sería la manera de presionar a los propietarios e instituciones para parar los alquileres abusivos.

De esta forma, la idea es ofrecer una respuesta conjunta a un reto que, aunque se vive de forma individual, no deja de tener una incidencia amplia sobre el tejido social del barrio. Entre las decisiones tomadas por la Comissió estuvo abrir un punto de información permanente en el Poblenou, justo en el Casal del Barri situado en la Rambla, y organizarse a un nivel territorial mayor, de ciudad, con otros colectivos que mantienen objetivos similares. Así, en marzo de este mismo año, \#EnsPlantem y la Comissió participaron en el evento Coordinem- 
nos! Trobada de col.lectius en lluita per l'habitatge. En Coordinem-nos se llevaron a cabo diferentes talleres informativos sobre cuestiones como los desahucios, el acompañamiento, la okupación o la legislación vigente en torno al alquiler.

Sin embargo, la acción en la que ha participado \#EnsPlantem y que más impacto, al menos a nivel mediático ${ }^{27}$, ha tenido ha sido Mudança de Protesta, en mayo de 2018 (Ver Figura 5). La idea tras esta iniciativa era poner de manifiesto, a través de la organización y acompañamiento de una mudanza simbólica, los denominados "desahucios invisibles", esto es, aquellos que se producen no tanto porque los inquilinos no puedan pagar la hipoteca o el alquiler -aunque a veces el nivel de la subida lo imposibilita-, sino porque los propietarios deciden, unilateralmente, no renovar los contratos y expulsar a los alquilados, de forma que, tras una reformas, pueden volver a poner el inmueble en el mercado a precios marcadamente superiores. Tal y como señala la web de la acción,

Los barrios de Barcelona se están vaciando de vecinos de forma silenciosa. Estos desahucios invisibles son consecuencia en gran parte de la finalización de 44.000 contratos de alquiler que se prevé que habrá en dos años y del abusivo aumento de los precios (un 20\% de media). Hace falta luchar para visibilizar esta grave situación y revertirla.

Decenas activistas y vecinos y vecinas del barrio acompañaron al camión de la mudanza por las calles del Poblenou denunciando que no se trataba de "una mudanza voluntaria" sino que "los especuladores nos expulsan del barrio" (López-Vallejo, 2018).

27 Entre otras TV3 http://www.ccma.cat/324/elsveins-del-poblenou-es-muden-en-protesta-contra-la-pressio -immobiliaria/noticia/2853910/, El Periódico https://www. elperiodico.com/es/amp/noticias/barcelona/solidaridadvecinal-contra-los-desahucios-invisibles-6801513? twitter_impression=true, El País https://elpais.com/ccaa/ 2018/05/05/catalunya/1525532706_381513.html?id_exter no_rsoc=whatsapp y Betevé http://beteve.cat/mudanca-protes ta-especulacio-immobiliaria-poblenou/

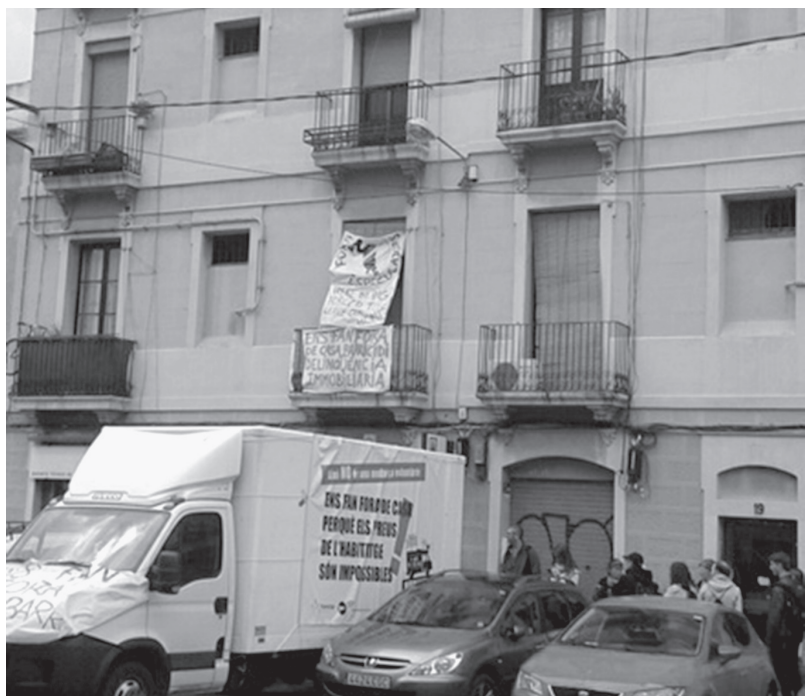

Figura 5. La mudanza de protesta en el Poblenou (10-052018). Fuente: Propia

\section{Los cambios en el paisaje urbano}

En cuanto a los cambios producidos en la fisionomía del entorno y la estructura productiva del barrio, las estadísticas del Ayuntamiento de Barcelona parecen dar la razón a aquellos que piensan que, efectivamente, está cambiando, esto es, que el Poblenou se está terciarizando. Así, según el informe realizado por el Gabinet Tècnic de Programació municipal, entre los años 2010 y 2016, la actividad vinculada al turismo y la hostelería pasó de representar el 5,6\% al 9,9\%, es decir, un incremento de casi el $77 \%$, mientras que el comercio tradicional y la industria pasaron, respectivamente, desde el $28,7 \%$ al $25,4 \%$, y del $50,3 \%$ al $37,7 \%$, durante el mismo periodo ${ }^{28}$.

Los efectos de esta dinámica ha llevado a que, para finales de 2017, en el Distrito de Sant Martí hubiera censados 37 establecimientos turísticos entre hoteles, apartamentos y pensiones- con más de 11.500 plazas, cuando solo cinco años antes,

28 Las mismas estadísticas indican que el sector de oficinas pasó del 8,8\% al 16,4\%, lo que podría reflejar la importancia e influencia de la puesta en marcha del Distrito 22@. Para más información ver: http://www.bcn.cat/estadistica/castella/ documents/barris/68_MA_Poblenou_2017.pdf 
en 2010, únicamente existían 29 de ellos, lo que suponía un total de 9.679 plazas. A esto habría que sumar unas 2.324 plazas en pisos completos ofertadas en la plataforma Airbnb ${ }^{29}$, con un incremento de más del $25 \%$ en el periodo antes señalado (Ajuntament de Barcelona, 2016a).

Las actividades de \#EnPlantem en torno a esta situación, no solo se basaron en la ocupación simbólica y material de solares cercanos a hoteles en construcción, tal y como se he comentado con anterioridad, sino también en distintas acciones destinadas a denunciar la relación que la transformación del barrio en destino turístico estaba teniendo sobre la vida cotidiana de sus vecinos y vecinas. Así, volviendo a la manifestación del 5 de mayo de 2017 que fue tildada, desde diferentes ámbitos y medios de comunicación, como una demostración de turismofobia por contar, en su recorrido, con el lanzamiento de globos de pintura y botes de humo a la fachada de un hotel, Robert, de nuevo, nos comenta que

"No pasó nada del otro mundo. Unos trescientos vecinos y vecinas se manifestaban y realizaron dos acciones de carácter simbólico (algunos huevos con pintura y un bote de humo) para evidenciar algunos de los culpables de la gentrificación y sustitución social que sufre el vecindario del Poblenou (empresas hoteleras, inmobiliarias, fondos de inversión...)".

29 Es necesario señalar, sin embargo, que algunos de los pisos que se ofrecen a través de Airbnb cuentan con licencia HUT, es decir, que también formarían parte de la oferta reglada de alojamientos turísticos en el barrio. Como Airbnb no tiene la obligación de pedir a sus anunciantes el código HUT es imposible saber el número total que cuenta con licencia y cuáles no. Sin embargo, una revisión detenida de la oferta del portal muestra que en torno a 89 de las viviendas ofrecidas podrían contar con licencia HUT legal. Esto supondría que habría que restar a los 236 estos 89 para conocer la oferta real no regulada del portal. Por otro lado, algunas veces, pisos completos son ofrecidos por habitaciones, en vez de por unidad. Esto hace que, posiblemente, la oferta de Airbnb en el Poblenou sea mayor de la que muestra la web de insideairbnb.com. Sea como fuera, ambos factores podrían equilibrar el número final, no afectando significativamente la aproximación de 236 viviendas completas totales.
Tanto diferentes grupos políticos, como parte del sector hostelero de la ciudad, se lanzaron inmediatamente a los medios a criticar la acción y exigieron al Ayuntamiento de la ciudad que "pusiera fin a la turismofobia” (Benvenuty, 2017) ${ }^{30}$.

Desde \#EnsPlantem, sin embargo, tienen una visión diferente sobre el tema, así como su propio análisis de la situación,

"Estábamos en un contexto donde decenas de vecinos y vecinas se veían forzadas a abandonar sus casas en la calle Llull ${ }^{31}$ por las obras de dos hoteles -los hoteles del solar de la Vanguardia-. Se quería poner de manifiesto la problemática de la especulación inmobiliaria. Creo que el lobby turístico se puso nervioso y movieron (sic) sus contactos. Los partidos políticos salieron a condenar una movilización vecinal".

Además de estas acciones, la plataforma mantuvo una línea de acercamiento con distintos grupos políticos e instituciones municipales (Ver Figura 6.) con el objetivo de, por un lado, dar a conocer la situación que estaba viviendo el barrio y, por otro, tratar de influir en la regulación municipal vinculada al control y planeamiento de las instalaciones y equipamientos turísticos que, a lo largo de 2016 y 2017, se estuvo discutiendo en el Ayuntamiento.

30 Desde el Gremi d'Hotelers de la ciudad se señaló que "Ni siquiera el alcalde accidental, Gerardo Pisarello, condenó los hechos de un modo contundente [...]. Aquello no fue ni acto simbólico, ni performance, tal y como declaró uno de los organizadores por televisión. Fue un acto de violencia. Y exigimos al Ayuntamiento que ponga fin a la criminalización y demonización del turismo, que dejen de poner en duda sus bondades y de destacar siempre sus problemas. Además, está lloviendo sobre mojado". Para más información ver: http://www. lavanguardia.com/local/barcelona/20170509/422401678446/ turismofobia-hoteleros-ayuntamiento-ada-colau-vandalismo.html

31 En marzo de 2017, tres bloques de viviendas de la calle Ramon Llull tuvieron que ser desalojados por peligro de derrumbe. Justo enfrente se estaban construyendo dos hoteles, a los que se responsabilizó inmediatamente de la cuestión. Para más información ver: http://www.lavanguardia.com/ local/barcelona/20170315/42900776476/desalojados-tresedificios-calle-llull-poblenou-grietas-hotel.html 


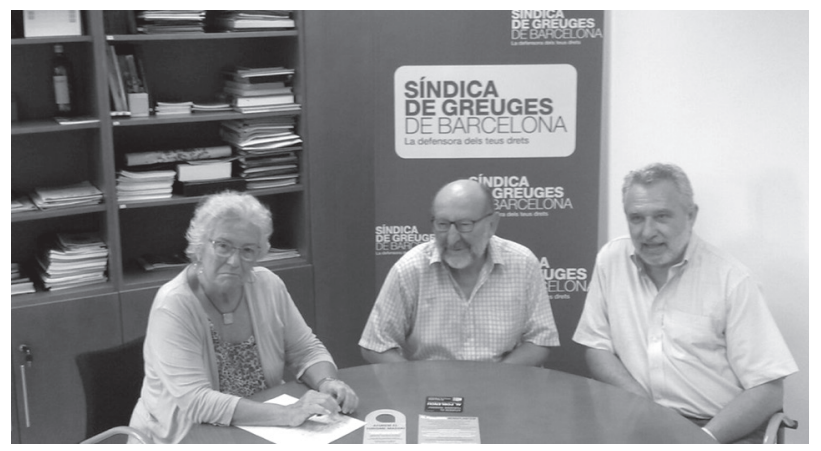

Figura 6. Reunión de representantes de \#EnsPlantem con la Síndica de Greuges (05-08-2016). Fuente: @EnsPlantemP9

Los resultados de ésta y otras acciones fueron satisfactorios pues el 27 de enero de 2017, el Pleno Municipal aprobaba el Pla Especial Urbanistic d'Allotjaments Turístics (PEUAT), el cual consideraba al barrio del Poblenou como Zona 1, esto es, aquella donde no se permite la implementación de ningún nuevo tipo de establecimiento turístico ni la ampliación de plazas de los establecimientos existentes $^{32}$.

\section{La privatización de calles y plazas}

Las actividades de \#EnsPlantem continuaron, a lo largo de 2016, con distintas acciones relacionadas con los ejes de denuncia anteriormente reseñados. Así, el día 14 de junio se organizó otra asamblea, seguida de una cena improvisada, y el 26 de julio una cacerolada en la propia Rambla del Poblenou (Ver Figura 7). El objetivo de ambas acciones fue, primero, realizar una reapropiación vecinal de un espacio altamente significativo del barrio el cual, según la plataforma, había sido tomado por bares y restaurantes mediante la disposición de sus terrazas y, segundo, sumar más gente a la plataforma. La importancia de la recuperación de un espacio urbano del barrio que se considera tomado o privatizado queda reflejada en acciones como ésta, pero también en comentarios y opiniones como la de Pierre, francés afincado en el barrio, cuando señala que

32 Para más información ver: http://ajuntament.barcelona. cat/pla-allotjaments-turistics/es/

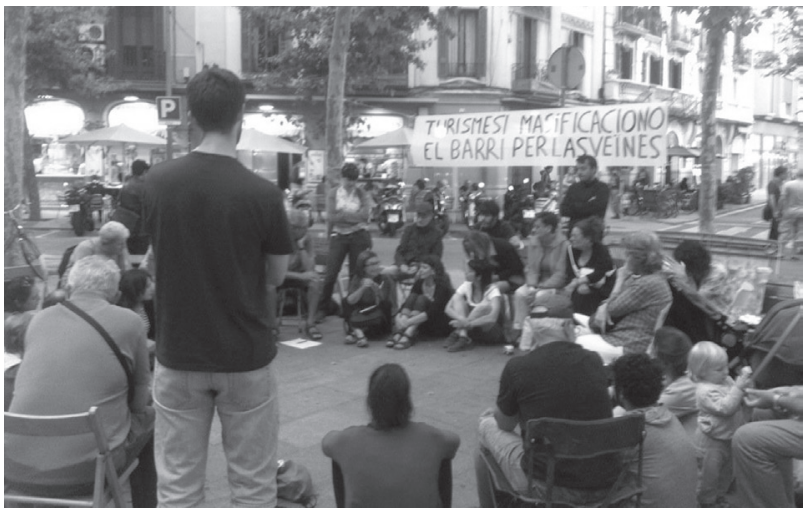

Figura 7. Asamblea-cena de \#EnsPlantem en la Rambla (14-06-2016). Fuente: @EnsPlantemP9

"el hecho de que al pasear la Rambla y escuchar a la gente hablar en inglés, y están de paso, pues ves una ocupación del espacio público que no es de la gente que vive en el barrio, sino que están de paso y vienen a consumir la ciudad y el barrio...."

El incremento sustancial del número de alojamientos turísticos antes reseñado se ha visto acompañado, además, de un importante incremento en la privatización del espacio urbano del barrio. Las calles y plazas del Poblenou se han visto pobladas, a lo largo de los últimos años, de mesas y sillas de terrazas de bares y restaurantes, con especial incidencia en la principal arteria del barrio, la Rambla del Poblenou.

Tal y como puede verse en la Figura 8 entre los años 2010 y 2018, el espacio ocupado por las terrazas se vio multiplicado por diez, alcanzando los $852 \mathrm{~m}^{2}$, aunque con un pico de $947 \mathrm{~m}^{2}$ en 2016, mientras que las licencias pasaron de 12 a 56 para el mismo periodo $^{33}$.

En noviembre de 2016, el Ayuntamiento aprobó, finalmente, la ordenación singular de las terrazas de la Rambla del barrio, tal y como estaba previsto en la Ordenança de Terrasses del año 2013 para

33 El periodo de crecimiento más exponencial, entre 2013 y 2015, coincide con los años del Gobierno de Convergència i Unió (CiU) al frente del Ayuntamiento de Barcelona que, de hecho, aprobó una nueva Ordenanza de Terrazas mucho más permisiva que la anterior, impulsando enormemente el número de licencias. 
Evolución Terrases Rambla Poblenou

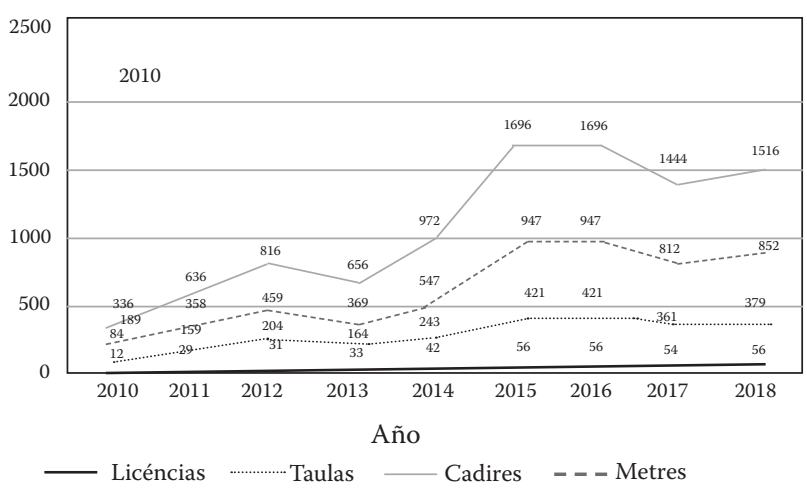

Figura 8. $\mathrm{N}^{\circ}$ de licencias anuales, $\mathrm{n}^{\circ}$ de mesas y superficie ocupada por las terrazas en la Rambla del Poblenou (20102018). Fuente: Ajuntament de Barcelona, 2018

determinados emplazamientos a consecuencia "de la estructura del espacio o cualquier otra circunstancia peculiar"34. Dicha ordenación prevé una ocupación máxima del 40\% del ancho del paseo y hasta un máximo de 42 mesas por cada 100 metros lineales. Además, se fija un máximo de hasta 445 mesas para la totalidad de la Rambla. La aprobación de dicha ordenanza muestra una disminución temporal de las mismas, pasando de las 421 del año 2016 a las 361 del año siguiente. Sin embargo, en 2018 el número de terrazas comienza, de nuevo, su escalada, situándose en las 379. Según un miembro técnico de Barcelona en comú del Districte Sant Martí,

La reducción de los dos últimos años, en aplicación de la ordenación singular, es bastante bestia (sic) en el tramo central, pero queda 'maquillada' por la ampliación de licencias que ha sido posible en los tramos superiores a Pere IV, es decir, la Rambla Nova.

Así, como consecuencia de la entrada en vigor de la nueva normativa, el espacio central de la Rambla, situado entre las calles Pere IV y Taulat, sí que ha visto disminuir su concentración de mesas y sillas de terrazas, pero esto se ha visto compen-

34 Boletín Oficial de la Provincia de Barcelona (BOPB). Para más información ver: https://bop.diba.cat/scripts/ftpisa. aspx?fnew?bop2013\&12\%2F022013032523.pdf\&1

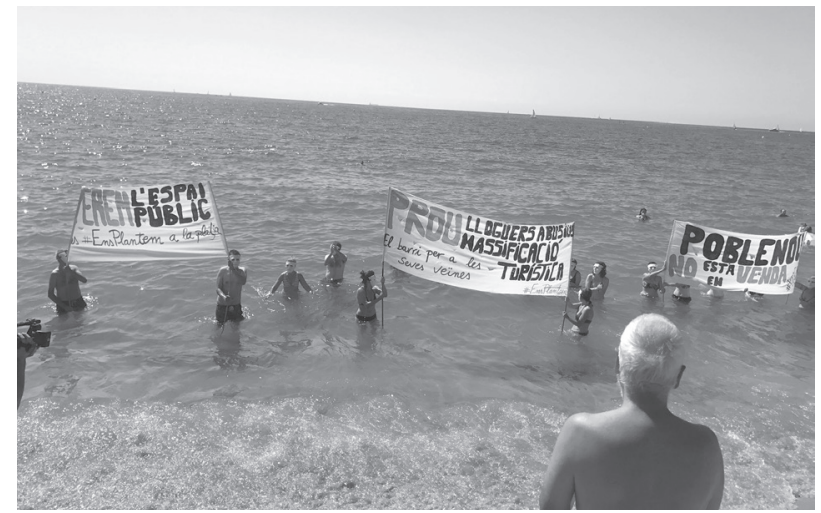

Figura 9. Acto de protesta en la playa de la Marbella (09-072017). Fuente: @EnsPlantemP9

sado con su incremento en la parte superior de la misma, esto es, entre Pere IV y Diagonal. Esta es la razón por la que hay una aparente disminución en el número de mesas, sillas y superficie, pero un mantenimiento del número de licencias.

Este resultado no inesperado de la puesta en marcha de la ordenación singular he llevado a los miembros de \#EnsPlantem a exigir una reforma de la misma más exigente y a participar, conjuntamente con otros colectivos de la ciudad, en una demanda colectiva por una "una política de inspección y sanción seria y rigurosa" ${ }^{35}$.

Por último, la denuncia que \#EnsPlantem lleva a cabo sobre la privatización del espacio urbano del barrio se amplia, además, a las playas próximas (Ver Figura 9). Así, un pequeño grupo de activistas recorrió la Rambla del Poblenou en julio de 2017 exigiendo recuperar el espacio público de las playas, copado por "las hamacas de pago que ocupan el espacio de la arena" (Beteve, 2017) ${ }^{36}$.

\section{Conclusiones}

El espacio urbano de las ciudades contemporáneas, como espacio social, esto es, aquel donde se proyectan las estructuras sociales, las repre-

35 Para más información ver: https://twitter.com/AssBa rrisTS/status/975275840798937089

36 Para más información ver: http://beteve.cat/nova-pro testa-poblenou-contra-massificacio-turistica/ 
sentaciones y los mitos de la sociedad, es también el espacio donde se manifiestan los conflictos generados por las diferentes clases sociales, etnias, sexos, etc. que la componen (Herin, 1982). En la Barcelona contemporánea, la importancia que el turismo y sus actividades ha acabado alcanzando en el sistema socio-productivo local ha dotado de características propias esta conflictividad; una conflictividad que, como avanzan las consignas que figuran en algunas paredes, es, en realidad, una manifestación de la lucha de clases.

La puesta en valor de elementos patrimoniales, bienes naturales y culturales, espacios y entramados sociales anteriormente ajenos a las dinámicas mercantiles ha generado una respuesta social articulada y específica -calificada injustamente como turismofobia desde determinados mediosque subraya y ataca algunos de los principales impactos que la turistificación ha hecho aflorar: la subida de los precios de la vivienda, los cambios en la estructura productiva local y el paisaje urbano, y la privatización del espacio público de algunas de las más significativas calles y plazas de los barrios.

La plataforma \#EnsPlantem, Vecinos en Peligro de Extinción, ha desarrollado, desde su nacimiento en mayo de 2016, todo un amplio abanico de respuestas a las tensiones urbanas sobrevenidas. Como movimiento social ha destacado, principalmente, por la variedad de acciones realizadas, las cuales han ido desde la ocupación simbólica y material de solares abandonados y espacios públicos emblemáticos del barrio, pasando por la propia incidencia política frente a partidos e instituciones, hasta llegar a la organización de manifestaciones, desfiles y asambleas abiertas de denuncia y propuesta de alternativas.

$\mathrm{Su}$ coordinación con otras organizaciones, tanto barriales -Comissió d'Habitatge- como a nivel de ciudad, ha quedado también patente. La continuidad manifiesta de \#EnsPlantem con iniciativas anteriores del mismo Poblenou -la Assemblea Social del Poblenou (ASP9), la Flor de Maig, etc.ejemplifica la constante efervescencia que generan las políticas neoliberales implementadas en Barce- lona a lo largo de las últimas décadas; unas políticas en las que, como señala Sara Gonzalez (2005), siguiendo a Harvey (1985), tiene mucha importancia la escala, ya que los procesos de acumulación del capital tienen una coherencia estructural temporal, de forma que el conflicto tiende a contenerse y canalizarse en su salto, haciendo necesaria la articulación de propuestas a distintos niveles territoriales para hacerle frente. Es precisamente esta disputa en torno a lo glocal (Swyngedouw,1997) lo que ha llevado a \#EnsPlantem a coordinarse a nivel ciudad con movimientos como la Assemblea de Barris per un Turisme Sostenible (ABTS), y este, a su vez, a crear y participar últimamente en la red \#SETNet (Ciudades y Regiones del Sur de Europa contra la Turistificación) $)^{37}$.

En definitiva, la orientación socioeconómica decididamente turística de la capital de Catalunya parece asegurar la continuidad de la inherente conflictividad urbana de la ciudad contemporánea. Queda por dilucidar, algo que restaría para posteriores investigaciones, si los movimientos sociales surgidos en respuesta a dicha orientación han sido capaces de hacer oír su voz, de forma que sus propuestas han sido tomadas en consideración, y si su articulación con distintos niveles territoriales ha logrado articular una respuesta coherente y a mayor escala.

\section{Referencias bibliográficas}

Ajuntament de Barcelona (2015). El sector turístico en Barcelona. Barcelona: Ajuntament de Barcelona - Barcelona Activa.

Ajuntament de Barcelona (2016a).22@Barcelona, 2000-2015. EldistrictedelainnovaciódeBarcelona http://www.ajuntamentbarcelonapremsa.info/ download/22_15_ANYS_CATALA_p.pdf[Consultado el 14 de mayo de 2018]

37 Para más información ver: https://assembleabarris. wordpress.com/2018/04/26/roda-de-premsa-resentacio-dela-xarxa-setnet-del-seu-manifest-fundacional-i-del-2n-forumveinal-sobre-turisme-18-i-19-de-maig/ 
Ajuntament de Barcelona (2016b). Plan Estratégico de Turismo de Barcelona 2020. Diagnosis estratégica Recuperado de http://ajuntament. barcelona.cat/turisme/sites/default/files/diagnosi_estrategica_v_1_esp.pdf

Aricó, G., Mansilla, J. A. y Stanchieri, M. L. (2016). La salvaguarda interrumpida del poder de clase. Una visión alternativa a la 'teoría de las etapas' en el urbanismo barcelonés. En Arico, Giuseppe, Mansilla, José Antonio y Stanchieri, Marco Luca (Coords.), Barrios Corsarios. Memoria histórica, luchas urbanas y cambio social en los márgenes de la ciudad neoliberal (pp. 215-255). Barcelona: Pol.len Edicions.

Arroyo, F. (1999). Barcelona construyó la Villa Olímpica sobre los restos de un área industrial degradada. El País. Recuperado de http://elpais.com/diario/1999/11/19/andalucia/942967331_850215.html

Berg, B. L. (2007). Qualitative research methods for the social sciences. Boston: Allyn and Bacon.

Bernard, H. R. (2006). Research methods in anthropology: Qualitative and quantitative approaches. Lanham: Altamira Press.

Benvenuty, L. (2017). Los hoteles exigen a Colau que ponga fin a la turismofobia. La Vanguardia. Recuperado de http://www.lavanguardia.com/ local/barcelona/20170509/422401678446/ turismofobia-hoteleros-ayuntamientoada-colau-vandalismo.html

Bourdieu, P. (1997) Razones prácticas. Sobre la teoría de la acción. Barcelona: Anagrama.

Brenner, N., Peck, J. y Theodore, N. (2015). Urbanismo neoliberal. La ciudad y el imperio de los mercados". En Observatorio Metropolitano de Madrid (Ed.), El mercado contra la ciudad. Globalización, gentrificación y politicas urbanas (pp. 211-244). Madrid: Traficantes de Sueños.

Caimanque, R. (2015) Regeneración urbana y la disputa por el espacio urbano: el caso de Valparaíso, Chile. En Aricó, G., Mansilla, J.A. y Stanchieri, M.L. (coord.) Mierda de ciudad. Una rearticulación crítica del urbanismo neoliberal desde las ciencias sociales ( pp. 32-44). Barcelona: Pol.len Editorial.

Capel, H. (2005). El Modelo Barcelona: un examen crítico. Barcelona: Ed. El Serbal.

Capel, H. (2016). La forma urbana en la ciudad postcapitalista. Biblio3W, Revista Bibliográfica de Geografía y Ciencias Sociales, Vol. XXI, nº1.177. Recuperado de http://www.ub.edu/geocrit/b3w1177.pdf

Castán, P. (2018). Barcelona batió sus récords de turismo de congresos en el 2017. El Periódico. Recuperado de https://www.elpe riodico.com/es/barcelona/20180502/bar celona-batio-sus-records-de-turismo-de-con gresos-en-el-2017-6795414

Castells, M. (1976). La cuestión urbana. Madrid: Siglo XXI.

Castells, M. (1986) La ciudad y las masas. Sociología de los movimientos sociales urbanos. Madrid: Alianza Editorial.

Charnock, G., Purcell, T. y Ribera-Fumaz, R. (2014). City of rents: The limits to the Barcelona model of urban competitiveness. International Journal of Urban and Regional Research, Vol. 38.1, 198-217.

Clarós, S. (2013). El 22@ no s'acaba d'integrar al Poblenou. En La Veu del Carrer, n¹8, 9.

Cordero, A. (2006). Nuevos Ejes de Acumulación y Naturaleza. El caso del turismo. Buenos Aires: CLACSO.

Delgado, M. (2003). Elogi del vianant. Del "Model Barcelona" a la Barcelona real. Barcelona: Edicions de 1984.

Delgado, M. (2007). La ciudad mentirosa. Fraude y miseria del "Modelo Barcelona". Madrid: Libros de la Catarata.

Delgado, M. (2017) Lo urbano más allá de la ciudad. En Henri Lefebvre, El derecho a la ciudad. Madrid: Capitan Swing.

Della Porta, D. (2009). Social movement studies and political violence. Centre for Studies in Islamism 
and Radicalisation. Recuperado de http://ps.au. $\mathrm{dk} /$ fileadmin/site_files/filer_statskundskab/ subsites/cir/pdf-filer/Forside_h\%C3\%A6fte4.pdf

Diani, M. (1992). The concept of social movement. The sociological Review, vol. 40, $\mathrm{n}^{\mathrm{a}} 1,1-25$.

Diani, M. (2010). Struggling Movements in Dubious Opportunities - An Afterword to 'Surviving Neoliberalism: The Persistence of Australian Social Movements. Social Movement Studies, vol. 9, n 2, 229-233.

Diani, M. y Della Porta, D. ([1999] 2006). Social movements. An introduction. Oxford: Blackwell Publishing.

Díaz Parra, I. (2009). Sevilla, cuestión de clase. Sevilla: Atrapasueños.

Díaz Parra, I. (2016). Sevilla 1929-1992. La producción de una mercancía. En Grupo de Estudios Antropológicos La Corrala (Ed.), Cartografía de la ciudad capitalista. Transformación urbana y conflicto social en el Estado español (pp. 195-118). Madrid: Traficantes de Sueños.

Florida, R. (2009a). Las ciudades creativas. Porqué donde vives puede ser la decisión más importante de tu vida. Barcelona: Grupo Planeta.

Florida, R. (2009b). La clase creativa: La transformación de la cultura del trabajo y el ocio en el siglo XXI. Barcelona: Grupo Planeta.

Fuller, H. y Michel, B. (2014). 'Stop Being a Tourist!' New Dynamics of Urban Tourism in BerlinKreuzberg. International Journal of Urban and Regional Research, vol. 38.4, 1.304-1.318.

García Herrera, L. M., Smith, N. y Mejías, M. A. (2007). Gentrification, displacement and tourism in Santa Cruz de Tenerife. Urban Geography, 28, 3, 276-298.

Giner, S. (1976). Sociología. Barcelona: Ediciones 62.

González, S. (2005). La geografía escalar del capitalismo actual. Scripta Nova, Revista Electrónica de Geografía y Ciencias Sociales, Vol. IX, núm. 189. Recuperado de http://www.ub.edu/geocrit/ sn/sn-189.htm

Guterman, B., Sánchez, F. y Laiber, P. (2015). Río Olímpico 2016: ciudad maravillosa es la que lucha. En Aricó, Giuseppe, Mansilla, José Antonio y Stanchieri, Marco Luca (coord.) Mierda de ciudad. Una rearticulación crítica del urbanismo neoliberal desde las ciencias sociales (pp. 110-122). Barcelona: Pol.len Editorial.

Gruter, M. (2013). Impactos negativos del turismo. En Torres Lezama, Vicente y Araujo, Edward Pierre (comp.) Antropología del Turismo. La industria sin chimeneas (pp. 63-70). Cuzco: Tinkuy.

Harvey, D. (1985). The Urbanization of Capital. Oxford: Blackwell.

Harvey, D. (2001). Espacios del capital. Hacía una geografía crítica. Madrid: Akal.

Harvey, D. (2007). Breve historia del neoliberalismo. Madrid: Akal.

Harvey, D. (2013). Ciudades rebeldes. Del derecho a la ciudad a la revolución Urbana. Madrid: Ed. Akal.

Herin, R. (1982). Herencias y perspectivas en la geografía social francesa. Geo-Crítica: Cuadernos Críticos de Geografía Humana, nº41, 26-33. Recuperado de http://www.ub.edu/geocrit/ geo41.htm

Hiernaux, D. y González, C. I. (2014). Turismo y gentrificación: pistas teóricas sobre una articulación. Revista de Geografía Norte Grande, n56, sept. 2014. Recuperado de https://scielo. conicyt.cl/scielo.php?script=sci_arttext\&p id $=$ S0718-34022014000200004

Huete, R. y Mantecón, A. (2018). El auge de la turismofòbia, ¿hipótesis de investigación o ruido ideológico?. Revista PASOS, vol. 16, n¹, 9-19.

Judd, D. (2003). Visitors and the spatial ecology of the city. En Hoffman, Lily M., Fainstein, Susan and Judd, Dennis R. (Eds.), Cities and Visitors. Regulating people, markets and city space (pp. 23-38). Oxford: Blackwell Publishing.

Judd, D. and Parkinson, M. (Eds.) (1990). Leadership and urban generation: Cities in North America and Europe. Thousand Oaks: Sage Publications. 
La Vanguardia (2016). Ocupación simbólica de un solar en el Poblenou contra la construcción de dos nuevos hoteles. La Vanguardia. Recuperado de http://www.lavanguardia.com/local/ barcelona/20160606/402320665446/ocupacion-solar-poblenou-turismo-hoteles.html

Lefebvre, H. (2013). La producción del Espacio. Madrid: Capitán Swing.

Lloyd, Richard (2002). Neo-bohemia. Art and neighborhood redevelopment in Chicago. Journal of Urban Affairs, vol. 24, 5, 517-532.

López-Vallejo, H. (2018). Solidaridad en el Poblenou contra los 'desahucios invisibles'. El Periódico. Recuperado de https://www. elperiodico.com/es/barcelona/20180505/ solidaridad-vecinal-contra-los-desahuciosinvisibles-6801513

Makhlouf, M. (2014). Transformaciones urbanísticas y movimientos vecinales actuales. El caso de la Barceloneta, Barcelona. Actas del XIII Coloquio Internacional de Geocrítica, El control del espacio y los espacios de control. Recuperado de http://www.ub.edu/geocrit/coloquio2014/ Muna\%20Makhlouf\%20De\%20la\%20Garza.pdf

Mansilla, J. A. (2014). La Flor de Maig somos nosotros. Geografía urbana de la memoria en el Poblenou, Barcelona. Scripta Nova, Revista Electrónica de Geografía y Ciencias Sociales, Vol. XVII, 146 (137). Recuperado de http://www. ub.edu/geocrit/sn/sn-493/493-05.pdf

Mansilla, J. A. (2018a). "El curt estiu de la turismefòbia. Moviments socials i conflicte urbà en el barri del Poblenou, Barcelona. En Revista Andaluza de Antropología, nº15 (octubre 2018).

Mansilla, J. A. (2018b). "Espai, capital i cultura: el cas de la mesquita de Premià de Mar" [Reseña]. En Revista Andaluza de Antropología, n¹5 (octubre 2018).

Marrero, I. (2003). ¿Del Manchester catalán al SoHo barcelonés? La renovación del barrio del Poblenou en Barcelona y la cuestión de la vivienda. Scripta Nova, Revista Electrónica de Geografía y Ciencias Sociales, Vol. XVIII, n493
(05). Recuperado de http://www.ub.edu/geocrit/ sn/sn-146(137).htm

Mayer, M. (2016). Neoliberal Urbanism and Uprising Across Europe. En Thörn, Hakand, Mayer, Margit y Thörn, Catharina (ed.), Urban Uprisings Challenging Neoliberal Urbanism in Europe (pp. 57-92). Londres: Macmillan Publishers Ltd.

Medela, J. y Salguero, O. (2016). Granada(s), un tronco, muchas ramas. En Grupo de Estudios Antropológicos La Corrala (Ed.), Cartografía de la ciudad capitalista. Transformación urbana y conflicto social en el Estado español (pp. 249-274). Madrid: Traficantes de Sueños.

Milano, C. (2017) Turismobofia: cuando el turismo entra en la agenda de los movimientos sociales. Marea Urbana, ${ }^{\circ} 1$, pp. 5-8.

Navas Perrone, M. G. (2016). La vocación utópica del urbanismo: el caso de la Vila Olímpica de Barcelona. Actas del XIV Coloquio Internacional de Geocrítica, Las utopías y la construcción de la ciudad del futuro. Recuperado de http://www. ub.edu/geocrit/xiv-coloquio/MGabrielaNavas. pdf

Nicholls, W. (2008). The urban question revisited: the importance of cities for social movements. International Journal or Urban and Regional Research, vol. 32 (4), 841-859.

Posthill, J. (2015). Digital ethnography: 'being there' physically, remotely, virtually and imaginatively. Johnposthill.com. Recuperado de https://johnpostill.com/2015/02/25/digitalethnography-being-there-physically-remotelyvirtually-and-imaginatively/

Romero, C. (2001). Ciudad, cultura y turismo: calidad y autenticidad. Revista PH, 36, 100-109.

Russo, A. P. y Richards, G. (2016). Reinventing the local tourism. Producing, consuming and negotiating place. Bristol: Channel View Publications

Savall, C. (2017). La tensión entre vecinos y hoteles vive su primera altercado en Poblenou. El Periódico. Recuperado de https://www.elpe 
riodico.com/es/barcelona/20170506/una-mani festacion-contra-el-turismo-en-poblenoutermina-con-incidentes-6020291

Slater, T. (2011). Gentrification of the city. En The New Blackwell Companion to the City (pp. 571-585.). Londres: Ed Blackwell Publishing Ltd.

Smith, N. (Smith, [1996] 2012). La nueva frontera urbana. Ciudad revanchista y gentrificación. Madrid: Traficantes de Sueños.

Swyngedouw, E. (1997). Neither Global nor Local. 'Glocalization' and the politics of scale. En Cox, K. (ed.) Spaces of globalization. Reasserting the power of the local (pp. 137-166). New York: GuilfordPress.

Tatjer, M. (1973). La Barceloneta del siglo XVIII al Plan de la Ribera. Barcelona: Los Libros de la Frontera.

Tello, R. (1993). Barcelona post-Olímpica: De ciudad industrial a escenario de consumo. Estudios Geográficos, Tomo LIV, 212, 507-220.

Thörn, H. (2012). In between social engineering and gentrification: Urban restructuring, social movements and the place politics of open space. Journal of Urban Affairs, 34 (2), 153-168.

Thörn, H., Mayer, M.y Thörn, C. (2016). Re-Thinking Urban Social Movements, 'Riots' and Uprisings: An Introduction. En Thörn, Hakand, Mayer, Margit y Thörn, Cathatina (ed.), Urban Uprisings Challenging Neoliberal Urbanism in Europe (pp. 3-56). Londres: Macmillan Publishers Ltd.

Tilly, C. (1977). From mobilization to revolution. Michigan: Centre for Research on Social Organization.

Velasco, H. y Díaz de Rada, Á. (1997). La lógica de la investigación etnográfica. Un modelo de trabajo para etnógrafos de escuela. Madrid: Trottam.

Vera, M. (2018). La turismofobia vuelve a Barcelona. $A B C$. Recuperado de https://www.abc.es/ espana/catalunya/barcelona/abci-vuelve-turismofobia-barcelona-201806191033_noticia.html

Zúñiga, F. (2014). Nuevos usos del patrimonio arqueológico de el Tajín a través de los procesos de turistificación, mercantilización y espectacularización. En Anales de Antropología, n², vol. 48, 151-182. 